gressive models of science can be used to justify democratic institutions, or abhorrent political ideas, such as the "scientifically" inspired and executed "final solution" to the "scientific" problems of racial impurity.

Their "third danger", that sceptical approaches stifle progress, may have a grain of truth, and scientists would be illadvised to engage in too much philosophical sophistry at the laboratory bench. Nevertheless, the possibility of good work is not destroyed by reflection upon the complex nature of science. It is a mistake to think that philosophy can contribute directly to scientific methodology. It is an equally grave mistake to think that the naive motivating ideology of science can provide epistemological foundations. Such aspirations died with logical positivism.

The only thing that makes clear good sense in Theocharis and Psimopoulos is the claim that the privileged image of science has been diminished by the philosophical, historical and sociological work of past decades. One hopes this is the case. Grasping for special privilege above and beyond the world we make for ourselves - the new fundamentalism that Theocharis and Psimopoulos press upon us indicates bankruptcy of spirit luckily not yet widespread in the scientific community.

HARRY COLlins

Science Studies Centre,

University of Bath,

Claverton Down, Bath BA2 7AY, UK

\section{AIDS: Incubation or latency?}

SIR-It is commonly assumed that the clinical manifestations of AIDS (acquired immune deficiency syndrome) follow an 'incubation period' which may be as short as months or as long as many years. 'Incubation' indicates a continuous process that, starting with its determinant cause, will produce its full effect at a relatively fixed time in the future, like the incubation of an egg or of some infectious diseases. To speak of incubation, one must be reasonably certain that the process has a continuity in time that irrevocably links the effect to its cause. When the final effect requires, besides the initial cause, some further condition that may or may not arise in the future, we speak of 'latency'. The manifestation of a disease later in life following the presence of an inherited predisposing characteristic is typical of this case. The exact course of the development of AIDS following contact with the virus is not yet known, but the long and highly variable time between infection and symptomatic course clearly indicates that this is a case of latency rather than incubation.
The distinction of latency from incubation is not simply pedantic. The prolonged absence of symptoms in a large majority of those that have had contact with the virus is already indicative that in many probably most - of them the disease will never develop. The determination of the causes that end the latency of AIDS and bring about its symptomatic course can only be accomplished by a continuing investigation of the cases in which the disease is latent.

It therefore requires the full cooperation of those who are immunologically positive but have no clinical manifestations. Although the public health authorities of many countries, the United States first and foremost, have employed every means to inform the public of the seriousness of the disease, they have done nothing to convince it of the interest and importance of the participation in the research and prevention of the disease of those who are immunologically positive but have no manifest symptoms. In fact, the prejudices of the public against those it sees as potential carriers of the disease have been allowed to reach a point where a person who knows himself to be immunologically positive and has no other symptoms of AIDS would be well advised to hide the fact.

Proper information of the public, and most important the need to regain the confidence of those who have had contact with the virus but show no clinical symptoms, require that the implications of the AIDS infection be honestly presented. A suitable beginning would be the acknowledgement that infection is followed by an indetermined period of latency and that in most cases this may well turn out to be as long as the natural life of the individual.

Department of Biochemistry,

GREGORIO WEBER

University of Illinois,

Urbana, Illinois 61801, USA

\section{Leprosy vaccine}

SIR-I wish to comment on your news article on a new vaccine trial against leprosy being undertaken in Maharashtra, India ${ }^{\prime}$. Recognizing that $a$ third of all patients with leprosy are in the Indian subcontinent, the government of India has made a major commitment to the control of this disease. The UNDP/World Bank/ WHO Special Programme for Research and Training in Tropical Diseases has, through its immunology of leprosy (IMMLEP) programme, supported a number of research efforts to develop candidate vaccines against leprosy. A mixture of killed Mycobacterium leprae together with live BCG vaccine has been shown to be effective in preventing infection in animals. It is currently being tested in controlled trials in 29,000 contacts of leprosy patients in Venezuela and in a general population of 120,000 in the northern region of Malawi.

I wish, however, to correct two misstatements in your article, concerning the possibility that this vaccine may contain retroviruses and foreign DNA. In the light of the stringent procedures for purifying the bacilli from armadillo tissue, including their exposure to DNAase and extensive washing, followed by gamma radiation $(2.5 \mathrm{Mrad})$ and autoclaving ${ }^{2.3}$, the statement that this vaccine contains retroviruses and foreign DNA is entirely incorrect and unfounded.

WHO IMMLEP M. Leprae Bank,

R.J.W. REES

National Institute for Medical Research,

London NW7, UK

1. Jayaraman, K.S. Nature 328, 660 (1987)

2. WHO Report of the fifth meeting of the Scientific Working Group on the Immunology of leprosy. Protocol $1 /$ 79. TDR/SWG/IMMLEP (5) 80.3 (1980)

3. Rees, R.J.W. Int. I. Leprosy 51, 515-518 (1983)

\section{Genome mapping}

SIR-It is more in sorrow than in anger that I protest at the headline of your news story about our genetic linkage map ("Critics denounce first genome map as premature", Nature 329, 571; 1987). The headline seems strangely disconnected from the facts even as they are detailed in your account.

After correctly noting that we will make our probes freely available for research purposes, you report, "[Collaborative] is, however, applying for patents on the probes and stands to gain if (there are) . commercial applications".

Let me assure you that this entrepreneur fervently hopes we stand to gain. That is precisely why we invested $\$ 12$ million in this enterprise. Nature goes on to talk of "cries of commercialism", of anonymous stock analysts who criticize us for an approach to genome mapping "too grand and expensive" and of unnamed critics who accuse us of "scientific merchandising" for reporting our accomplishments.

We confess that we do want to make a buck, honestly. We think investing our shareholders' money in genetic linkage mapping is a good idea for science, and a good idea for our business. I think too much is being made of the gaps and not enough of the map.

If Collaborative Research makes money doing all this, colour us happy and colour those stock analysts green.

OrRIE M. Friedman

Collaborative Research Incorporated,

Two Oak Park,

Bedford,

Massachusetts 01730, USA

Letters submitted for Correspondence should be typed, double-spaced, on one side of the paper only 